\title{
The Impact of the Brain Keys Program Implementation to the Creative Thinking Development
}

\author{
Ihab Ahmed Mashaal \\ Patented of Brain Keys product \\ A Member of (NIA) \\ Dr. Eman Saeed Al-Bourini \\ Associate Professor \\ Educational Psychology Cognition \\ Princess Alia University College \\ Al-Balqa Applied University \\ Dr. Hassan Rafe'e Shaheen \\ Assistant Professor \\ Special Education Princess Alia University College \\ Al-Balqa Applied University \\ Dr. Ne'emat Adnan Hararah
}

\begin{abstract}
The current study aimed at identifying the impact of the Brain Keys Program implementation on the creative thinking development. Therefore, the study adopted the experimental approach by using the experimental and control groups design. The study sample consisted of (159) individuals from the community, (78 women- 81 children), were intentionally chosen, and divided among two groups, the experimental group consisted of (40 women -43 children) who have been applying the brain keys program, and the control group consisted of (38 women -38 children) who have not been applying the brain keys program .

In order to achieve the objectives of the current study; two tools were used, the first one: brain keys program of (Meshaal, 2011), and the second: Torrance Test for Creative Thinking (Torrance, 2001), which verified the validity for both tools, and the reliability for Torrance Test, and then they applied both of them on the study sample.

After the data analysis was used through using SPSS; the study results showed that there are significant differences in the mean results concerning the children and women sample tests at the levels of flexibility, originality and details concerning the creative thinking test in its formative forms (A and B), attributed to the application of the brain keys program, these differences tend to be in favor for the experimental group. This indicates that there is a statistically significant effect at the level of significance $(\alpha \leq 0.05)$ for applying the brain keys program at the levels of flexibility, originality and details concerning the creative thinking development on the Torrance test among study sample. This result revealed the positive and effective effects of the brain keys program, which raised the level of creative thinking among the study sample.

The study recommended to encourage and support the students to use the creative thinking in their Learning process and problems solving, in addition to working on the brain keys program by using the generalization among students at all academic levels, including schools and universities.
\end{abstract}

Keywords: Brain Keys Program - Creative Thinking Development.

\section{Introduction}

Thinking is one of the features that distinguish the human being from other creatures. Thus thinking is considered a continuous process that one exercises on daily bases, while the brain conducts a series of mental activities when it is exposed to stimulate that he receives from one of the five senses (Hamouri, 2004). 
Paul (2004) believes that thinking is a search for clarity, precision, reasoning and justice based on the mind in addition to an enthusiasm to reach the depth and roots of things, and a great deal of contradiction and inconsistency.

Thus thinking is a purposeful process, and mental activity that allows us to take care of solving the issue, interpreting data, making decisions, and understanding the ideas and concepts (McWhorter \& Perkins, 2003).

Paul (2004) emphasizes that the quality of one's thinking affects the quality of his life. But Salder, (1993) points out that for the person to succeed; he should have critical thinking skills and be able to have some educationalthinking strategies.

Coughlan (2010) adds that one way of preparing the individual for the future is to teach him how to think rather than to think.

Innovation is recognized as a process that solves problems and weaknesses, gaps, inconsistencies, lack of information, search for solutions, formulate hypotheses, in order to test them, reformulate them, or modify, communicate, and communicate outcomes to others, (Torrance, 1979).

George (1995) sees creativity as the individual's ability to produce. But Morrison (1996) goes on to say that creative thinking is some of the highest levels of thinking (analysis, synthesis, and evaluation), which set these levels of thinking.

Creativity is the unique process of human beings. It is the maximum level of excellence that the human mind can reach through the cognitive processing of things, situations, experiences and problems in a unique or unusual way, or by developing a set of previous solutions and coming up with a new solution. It is a kind of thinking that aims to wander through the multiple aspects of the mind, it is a way of touching some cells that are almost inactive for a long period of time and urge them to function (Edgar, Faulkner, Knobloch, \& Alan, 2008).

Fisher (2005) sees the creative process as a series of high-level cognitive processes that require an individual to think through situations, events and tasks in a thoughtful and in-depth manner that does not accept the processing of ideas and information in a simple or familiar level, but seeks to realize the mind to its fullest; Attention and sensitivity, which ensures the control of multiple cognitive processes on the one hand, and conscious escape from the confining of traditional ideas, and thus the production of new ideas on the other hand. (Qatami, Qatami, Jaber, Hamdi, Subhi, 1996, p. 33, De Bono, 1989, p. 27).

Stein (2004) has defined creative thinking as: the thinking that involves the multi-stage processes, through identifying the problem, the important aspects, and finding a new way to solve the problem.

Jarwan (2002) defines creative thinking as "a purposeful, intentional mental activity directed by a strong desire to seek solutions or to arrive at original products that were previously unknown." Creative thinking is comprehensive and complex. It is of the highest complexity of thinking, because it involves interconnected cognitive, emotional and moral dimensions that constitute a unique state of mind.

Lipman (1998) suggests that the levels of analysis, composition, and evaluation are among the highest levels of thinking, add to mention that there is a lack of analysis and reasoning, creative thinking, as well as mental evaluation and evaluation.

Add to mention that different views differed in their definition of the skills of creative thinking, and their classification differed too due to the overlap between the simple and higher thought processes as interrelated cognitive and cognitive skills. However, Keer (1997) asserts that different mental skills play an important role In the process of creative thinking, which includes: (fluency, detail, flexibility, originality, conversion, visualization, organization, analysis, installation and evaluation), in addition to the other skills at (Coughlan, 2010):

\section{- Fluency:}

The student's ability to generate many ideas, alternatives, questions, synonyms, or uses as he or she may interact with a situation requires a mind-set to solve or understand the problems involved, and a mind-driven work in which the student is motivated by his mental experience, To give the largest number of experiences at maximum speed and deeper performance, it is necessary to use a process of recall and optional recall of information, experiences or concepts that he /she has already learned in order to integrate with new the experiences and achieve the new creative performance or produce a number of ideas on a particular subject in a fixed time unit. The creative student has a high degree of fluency and ease Generation (Al-Sameer, 2003). 
Furthermore, fluency measurements take several forms: speed of thinking by giving words with a certain tone beginning with a particular letter or a certain section, giving words ending with a particular letter, as well as the mental activity in which the student is asked to classify the words in special categories or to classify ideas according to certain criteria, or give the greatest number of uses to specific objects such as: the book, the newspaper, the brickwork, giving a number of titles to topics or stories, or mentioning the greatest number of implications for a word, as well as the ability to use words in as many sentences and phrases as possible (Alotoom, 2004).

\section{- Flexibility:}

Flexibility means the ability of the student to generate a variety of ideas that are not the expected usually, guide or transform the thinking process as conditions change, and flexibility to reverse mental rigidity, which means adopting predetermined and unchangeable mental patterns as needed. Flexibility: Automatic flexibility, adaptive flexibility, flexibility to redefine or abandon an old concept or relationship to address a new problem. Examples include: Write a short article that does not contain any past verb, or think of all the ways you can use to avoid the cold of winter, in addition to paying attention to the quality of ideas (Jarwan, 2002).

\section{- Originality:}

The originality of thinking is the best skill related to creativity and creative thinking, namely the sense of novelty and uniqueness, and the search for rare ideas of repetition or acquisition, and the authentic idea is if it does not repeat the ideas of others and be new if judged in the light of ideas provided by others. These ideas are not subject to common ideas but are characterized by excellence, and the student of the original thinking does not generate ideas or traditional solutions to the situations or problems. The skill of knowledge originality differs in thinking about the skills of fluency and flexibility, as it does not indicate the quantity of creative ideas presented by the student, but rather depends on the value, quality, originality, and originality of these ideas (Jarwan, 2002).

Other researchers believe that there are two basic components of originality (Jarwan, 2012):

\section{- Elaboration (Details):}

It means the ability to add new and varied details to the idea or solution of a problem or panel, which will help to develop, enrich and implement.

\section{- Sensitivity to Problems:}

It is the awareness of the existence of problems, needs or weaknesses in an environment or a position. This means that some individuals are quicker than others when observing the problem and verifying its presence in the situation. Undoubtedly, the discovery of the problem is a first step. Whereas, in the search for a solution, and then add new knowledge or make improvements and modifications to existing knowledge or products, and is associated with this ability to observe unusual things, anomalies or baffling around the individual, re-employment or use and raise questions about them.

\section{Previous Studies}

A number of studies have been conducted on the creative thinking development in a variety of environments and on multiple samples. These studies were designed to develop creative thinking through pre-designed or specially designed programs, such as; the impact of creative thinking on creativity and cognitive achievement, these studies are: The study of Lin, \& Wu (2016), which aimed to identify the impact of creative thinking based on the Internet concerning the creativity of students and the Learning outcomes. In order of achieving the objectives of the study, the researchers applied the design of the experimental research, where a study sample formed of (186) universities and educational institutions in Taiwan that have been teaching the program applied to these university students for (4) months period. The results of the study showed positive effects of creative web-based teaching on creativity, the positive effects of creativity on learning outcomes, and the positive effects in teaching creative web thinking based on the learning outcomes.

The study of Hallajian, (2016) aimed to identify the relationship between creative thinking and computer games for high school students. The study relied on the analytical descriptive approach. The study sample consisted of secondary school students in Tehran who were in their academic year (2014-2015). 105 students, (54) females and (51) males, were selected from four schools by using a sample of multi-stage groups. The tools used in this study included creative thinking testing and a test of computer games by using assessment. 
The results showed that the four groups: (who did not use the computer games, and used games for less than an hour, and used games between (1-2) hours, in addition to the games for more than Two hours) were significantly different in the level of creative thinking. The results also revealed that there are statistically significant differences in innovations among the four groups without using less than one year, while using between one and two years and more than two years. Thus, the use of computer games leads to promoting the creative thinking among students. But in case the using of games has increased to some level, then the negative results are expected to appear.

The study of Khawaldeha, \& Ruzlan, (2016) aimed to test the impact of SCAMPER program on creative thinking of talented and gifted students at King Abdullah II School of Excellence in Jordan. The experimental quasiexperimental method was used, based on a sample of two groups. The experimental group consisted of (21) students and the control group consisted of (21) students. In addition to using the test of creative thinking to measure the creative thinking among students the results showed that SCAMPER program has a significant impact on creative thinking, as well as statistically significant differences between the pre-test and post-test of creative thinking due to the impact of SCAMPER program, and for the post-test. The results indicated the effectiveness of using the SCAMPER programs in creative thinking for gifted students. The study of (Lieu, Nhat, \& Robert, (2016) was designed to identify the perceptions of Vietnamese and international secondary school teachers and teaching creative thinking skills based on a preliminary analysis of 234 teacher surveys, 17 in-depth interviews, and 208 lesson plans. The results of the study indicate that teachers in the study sample can only teach creative thinking skills when required by policies and curricula. They often use familiar creations, and the results indicate that in order to promote and develop students' creative thinking skills, the teachers must be fully cognizant of creativity. Thus teaching creativity, required to develop and evaluate student creativity, to be trained in the use of creative tools.

The study of Al-Rashidi, Al-Khalidi, \& Zyoudi, (2015) aimed at identifying the level of creative thinking among gifted students in the secondary stage in Tabuk region in the Kingdom of Saudi Arabia in the light of some variables. In order to achieve the objectives of the study, the descriptive method was used. The results showed that gifted students have an average level of all creative thinking skills. The results also showed that the level of creative thinking among gifted male and female students is based on a sample of (94) students and (99) students with a total of 193 students. The results revealed that the level of the female students was higher than of males. The results showed a difference in the level of thinking in the classroom and for female students.

The study of Alrubaie, \& Daniel, (2014) aimed to develop the test of creative thinking among physics students in Iraqi universities. Based on the Torrance test for creative thinking tests and various other creative thinking tests in science education, the creative thinking test was specially designed for Iraqi physics students in the second intermediate stage. This test has been tested from creative thinking in terms of validity and reliability. The result showed that the test of creative thinking had adequate validity and reliability and the test could be successfully applied.

The study of Piaw (2014) aimed to identify the relationship between (gender and thinking style) and the ability to creative thinking, and also to recognize the impact of the interaction of personal factors on the ability of creative thinking. The study used the descriptive analytical method, and was conducted on a sample of (216) in the sixth grade. Students' mental thinking was measured through learning and thinking patterns, while the ability to think creatively was measured through the Torrance creative thinking test. By adjusting the three axes (race, academic ability, and ability to think critically), the results indicated that gender was strongly associated with the ability to think creatively, while the right brain thinking and learning style was positively and significantly associated with each of the five components and ability On creative thinking, (originality, fluency, flexibility), and results indicate that gender and style of thinking were important factors in the ability to think creatively. However, a large interactive effect of the two variables was not found on the ability to general creative thinking. The study of Hegazy (2012) aimed at revealing the impact of a proposed training program in the development of creative thinking among high school students in the Galilee region. The study sample consisted of (60) students who were selected by the purpose of the whole community, (30) students were taught in the usual way, and the experimental group consisted of (30) students who were taught using the proposed program, and used in the tribal and remote measurements Torrance test for creative thinking The image of the words "A" . The results showed the presence of there were statistically significant differences between the mean of the two groups on the Torrance test as a whole, and its three dimensions (fluency, elasticity, and originality) 
Were attributed to the method and were for the benefit of the experimental group; indicating the effectiveness of the proposed training program in the development of creative thinking among students are statistically significant between the averages on the test as a whole, attributable to gender, or the interaction between the variables of the method and sex.

\section{The study problem and its questions:}

The researchers noted that most of the studies who examined the concept, characteristics and characteristics of creative thinking were considered as gifted, and ordinary students in terms of measuring the level of creative thinking, and its relation to many related variables, or according to the impact of programs that were measured or adopted in previous studies of creative thinking. But this study also aimed to investigate the impact of the (brain keys program) among (Meshaal, 2011), when developing the level of creative thinking. The problem of the study has to do with answering the main question: Is there a statistically significant effect at the level of $(\alpha \leq 0.05)$ of the Brain Keys Program Implementation to the Creative Thinking Development on the Torrance test among the study sample?

\section{The following hypotheses have aroused from the main question:}

1- There is no statistically significant effect at the level of $(\alpha \leq 0.05)$ of the Brain Keys Program Implementation to the Creative Thinking Development at the level of flexibility on the Torrance test among the study sample.

2- There is no statistically significant effect at the level of $(\alpha \leq 0.05)$ of the Brain Keys Program Implementation to the Creative Thinking Development at the level of originality on the Torrance test among the study sample.

3- There is no statistically significant effect at the level of $(\alpha \leq 0.05)$ of the Brain Keys Program Implementation to the Creative Thinking Development at the level of adding details to the Torrance test among the study sample.

\section{Purpose of the study:}

This study aims to identify the effect of the brain-key program which is designed by (Meshaal, 2011) in the creative thinking development among a sample of children between their ages vary between $(7-12)$ years from both genders, and a sample of adults between their ages vary between (24 - 57) years only females.

\section{The importance of study}

- Theoretical importance: This study adds a dimension to the educational psychological dimensions. It also sheds light on the relationship between the new brain keys program designed by the researchers, in addition it develops the level of creative thinking on the Torrance scale. It also provides information and data that show the level and magnitude of this program's impact in developing the creative thinking level for children and adults.

- Practical importance: a new educational psychological program designed by researchers, the experience and success of this program in developing the level of creative thinking for children, adults and women, will enable the workers in the educational psychological field to use and rely on the teaching, the teaching processes and other Educational processes. This study should also be considered the first study in which the brain Keys program was used to influence the creative thinking level.

\section{Terminology of study}

\section{- Brain Keys Program}

Is a world-class integrated program based on scientific foundations presented for the first time in the world? It also aims to bring about a comprehensive and balanced change in the traditional thinking patterns by developing the highest thinking skills and raising the efficiency of the right half of the brain which is the least used. The program includes practical applications in the form of exercises and mental games, (1622/4/2015) under the name of Brain Keys Program (Meshaal, 2011).

\section{- Creative thinking}

It is characterized by a strong desire to search for solutions or find original products that were not previously known. It is characterized by comprehensiveness and complexity for it involves interrelated cognitive, emotional and moral elements that constitute a unique state of mind for the individual (Jarwan, 2012, Torrance, 1979, Guilford, 1985, DE Bono, 1996). 


\section{- Torrance Test for Creative Thinking (Torrance program):}

In 1988, Torrance formulated this training program, which includes the four skills of innovative thinking: fluency, flexibility, originality, and detail, so that individuals are trained in using the innovative methods such as quizzing, opening and brainstorming questions, Where the individual draws his imagination in the search for solutions to the questions and positions (Torrance, 2001).

\section{Methods and procedures}

\subsection{Methodology of the study}

This study was based on the experimental approach by using the design of two tests for two groups, (control group) which is considered as a measurement for the creative thinking level and its members by using the Torrance Test for creative thinking, furthermore, the other measurement was (the experiential group). Whereas, the level of creative thinking was measured using the Torrance Test of creative thinking together with the implementation of the brain keys designed by (Meshaal, 2011).

\subsection{The study Sample}

The study sample was selected by (159 individuals), (78 women- 81 children). The sample of the study was chosen (Intentional sample) according to the purpose of the study. It consisted of (159) individuals, (78) adults (were women from the community), in two groups: control group (38), and the experimental group (40), and (81) children, (38) in the control group and (43) in the experimental group.

\subsection{Study Tools}

\section{First tool: Brain Keys Program:}

This program in considered an integrated global program based on scientific foundations. The Brain Keys program is one of the best tools to help open new neurotransmitters between human brain cells. The first step also helps to look at the image completely, and then start from it to the pictured details. The program includes practical applications in the form of exercises and mental games, which are patented and intellectual property rights under the number (1622/4/2015) under the name of the brain keys (Brain Keys) in (Meshaal, 2011).

\section{Program goals:}

- Brain keys game designed for one player.

- Helps focus better.

- Improves memory strength and enhances intelligence level.

- Develops the ability to solve problems at an early age.

- Develops the ability to think creatively and thinking hyper (outside the box).

- The development of fine motor skills, and improve the skill of synergy and coordination between hand and eye.

- Develops control and control of the characteristics of the individual mood (such as apathy, impulsivity, impatience, speed and lack of concentration).

- Reduces the negative impact of excessive use of smart technology.

- Increases the individual's ability to see errors.

- Develops the planning and arranging processes in thinking solving the problem.

\section{The contents of the program:}

- It consists of a cardboard cube box which contains: 25 cubes, and a guide that contains a variety of shapes and designs of sports, engineering and environment.

- There are four funds for the game of brain Keys, depending on the levels of human mental growth:

- First level: early childhood (3-5).

- Second level: middle and late childhood (5-12).

- Third level: Beginner adults (from 12).

- Fourth Level: Advanced Adult (Adult-Age), which measures high-level performance skills that require aboveaverage intelligence for analysis, synthesis and application.

Each level consists of several drawings and forms, each drawing or shape is drawn for a short period of time. The researcher is asked to apply what he sees in the cube box, noting the performance of the subject through the cameras and observers and measuring the length of time to complete the work. 
The graphics and shapes in each level are easy to hard, and finish at the last level, the fourth in graphics, shapes and missions of a high degree of difficulty.

\section{Example of application session and observed note:}

(Offering exercise, or cube installation) for the examiner

To examine the qualitative calendar, through the method of eating exercise is revealed the different thinking processes of each examined, and habits of work, mood, and attitudes towards the self, and the level of visual perception - spatial .The trainee's methods of solving the problem reflect his / her practical and unusual mental habits. Arrangement and planning are among the characteristics of the work behavior shown by the intake of cubes. Some of the trainees always work in the same direction, from left to right and up and down, for example, while others work in the part where they might be busy. Most people realize that cubes are all the same, but some continue to manage each new cube required side. If it does not appear the first time, it looks at another cube, and others work quickly and recklessly, misrepresent the appropriate cubes in place, and overlook the errors as a result of negligence, while others appear slower but it works systematically and does not lead one movement unnecessarily, It is also possible to observe the mind habits of the trainee through his ability to see mistakes quickly, and correct them. Also, mood characteristics such as diligence, impulsivity, impatience and indifference can be observed, and the trainee's feelings towards themselves can be seen through self-deprecating phrases, selfcongratulations, requests for help or refusal to work.

\section{Validity of the brain keys program:}

In order to verify the Brain keys program, it was presented after the completion of its construction in its preliminary form to experienced group, and competent in the field of educational psychology to ensure the suitability of the program, the validity of its contents, validity of the objectives, and strategies used, as well as the number of sessions and the time required for it, Or delete. The researchers applied three training sessions taken from the program to ascertain the appropriateness of the concepts included in the program for the sample of the study, the timing of the sessions and the appropriateness of its application, and the appropriateness of the strategies and tools used to achieve its objectives.

\section{Second tool: The Torrance Test of Creative Thinking (Figure A-B) (Torrance, 2001):}

This test aims at measuring the abilities of creative thinking (details - originality - flexibility) in individuals before and after the application of the program used.

- The test consists of three activities, are as follows:

A. The first activity is to create the image (the curved shape is colored using a combination of letters, numbers, and shapes). This activity is a blank page; the lowest one is a title.

B. Activity 2: Complete the lines, and contains ten lines to be completed by the student to the forms and placement of the appropriate name of the resulting form.

C. Activity 3: The use of circles, and consists of (34) circle on two opposite pages; the first of which 9 circles matrix $3 \times 3$, and the second: 25 circuits $5 \times 5$ matrix.

\section{- Reliability and Stability Test Torrance:}

This test consists of three main abilities: Fluency, Flexibility and Originality, and the validity and reliability of this test were validated because it was applied to many studies such as (Mawafi, Muhammad, \& Malaka, 2003), which showed that the test has a high degree of honesty and consistency.

\section{A) Reliability of the Torrance test:}

The Torrance Test of Creative Thinking is one of the most innovative tests used in psychological and educational studies. The validity of the test has been confirmed in many psychological and educational studies and researches in many ways. It is the most widely used test in studies and research on creativity and creativity.

\section{B) Stability of the Torrance test:}

To verify the validity of the three capacity test, the researchers applied the test to 10 individuals of different ages. After a month, the test was re-applied to the individuals themselves (Test-retest) and Pearson correlation coefficient. Pearson correlates between the results in the first application and the results in the second application (0.81), thus testing is valid for use. 


\section{Results of the study and Discussion:}

After the study tools were clarified and the signs of its validity and stability, the scores obtained by the results of the sample were analyzed on the test of the creative thinking of Torrance. The hypotheses of the study were discussed as follows:

\section{1- Results of the first hypothesis and discussed:}

The first hypothesis of the study: There is no statistically significant effect at the level of $(\alpha \leq 0.05)$ of the Brain Keys Program Implementation to the Creative Thinking Development at the level of flexibility on the Torrance scale among the study sample). To validate this hypothesis, an independent sample t-test was performed. The results are shown in Tables (1) and (2).

Table (1): $t$ - test of the control and experimental groups on the creative thinking test at Flexibility level (Image format $\mathbf{A}$ )

\begin{tabular}{|c|c|c|c|c|c|c|}
\hline Level & Group & No & mean & S. Deviation & (t) value & Sig. value \\
\hline \multirow{2}{*}{ children } & Experimental & 43 & 36.67 & 13.22 & \multirow{2}{*}{12.44} & \multirow{2}{*}{$* * 0.000$} \\
\cline { 2 - 6 } & Control & 38 & 30.22 & 12.78 & & \multirow{2}{*}{11.07} \\
\multirow{2}{*}{ Women } & Experimental & 43 & 59.75 & 14.42 & \multirow{2}{*}{$* 001$} \\
\cline { 2 - 5 } & Control & 38 & 51.41 & 13.88 & \\
\hline
\end{tabular}

* Statistically significant at (0.05) level

** Statistically significant at (0.01) level

The data of the previous table indicate that there are statistical significant differences in the mean as a result of the test results of children sample at the level of flexibility on the creative thinking test in form (A), due to the application of the brain keys program, where the level of significance has reached (0.000). In favor of the experimental group in which the brain keys program was applied. The average results of children sample has reached (30.22) before the application of the brain keys program (control group), and reached after the application of the brain keys program (36.67) (experimental group), and this indicates the impact of the brain keys program in the creative thinking development in children, this impact has reached $(21 \%)$.

The data of the previous table indicate that there are statistical significant differences in the average results of the test of women sample at the level of flexibility on the creative thinking test in form (A), due to the application of the brain keys program, where the level of significance $(0.001)$. In favor of the experimental group in which the brain keys program was applied. The results of women sample (51.41) before the implementation of the brain keys program (control group), and reached after the application of the brain keys program (59.75) (experimental group), and this indicates the impact of the brain keys program in the creative thinking development in women, this impact has reached $(16 \%)$.

Table (2): $t$ - test of the control and experimental groups on the creative thinking test at Flexibility level (Image format B)

\begin{tabular}{|c|c|c|c|c|c|c|}
\hline Level & Group & No & mean & S. Deviation & (t) value & Sig. value \\
\hline \multirow{2}{*}{ children } & Experimental & 43 & 79.14 & 21.13 & \multirow{2}{*}{13.44} & \multirow{2}{*}{$* * 0.000$} \\
\cline { 2 - 7 } & Control & 38 & 68.22 & 20.11 & & \multirow{2}{*}{12.07} \\
\multirow{2}{*}{ Women } & Experimental & 43 & 101.25 & 25.30 & \multirow{2}{*}{$* 0.000$} \\
\cline { 2 - 5 } & Control & 38 & 92.66 & 22.78 & & \\
\hline
\end{tabular}

* Statistically significant at (0.05) level

** Statistically significant at (0.01) level

The data of the previous table indicate that there are statistical significant differences in the average results of the test of children sample at the level of flexibility on the creative thinking test in form (B), due to the application of the brain keys program, where the level of significance has reached (0.000). The experimental group in which the brain keys program was applied.

The results of children sample (68.22) before the implementation of the brain keys program (control group), and reached after the application of the brain keys program (79.14) (experimental group), and this indicates the impact of the brain keys program in the creative thinking development in children, this impact has reached (16\%). 
The data of the previous table indicate that there were statistical significant differences in the mean results of the test results of the women sample at the level of flexibility on the creative thinking test in form (B), due to the application of the brain keys program, where the level of significance has reached (0.000). In favor of the experimental group in which the brain keys program was applied. The results of the women sample (92.66) before the implementation of the brain keys program (control group), and after the application of the brain keys program (101.25) (experimental group), and this indicates the impact of the brain keys program in the creative thinking development in women, this impact has reached (9\%).

\section{2- Results of the second hypothesis and discussed:}

The second hypothesis of the study: There is no statistical significant effect at the level of $(\alpha \leq 0.05)$ of the Brain Keys Program Implementation to the Creative Thinking Development at the level of originality on the Torrance scale among the study sample. To validate this hypothesis, an independent sample t-test was performed. The results are shown in Tables (3) and (4).

Table (3): $t$ - test of the control and experimental groups on the creative thinking test at Originality level (Image format A)

\begin{tabular}{|c|c|c|c|c|c|c|}
\hline Level & Group & No & mean & S. Deviation & (t) value & Sig. value \\
\hline \multirow{2}{*}{ children } & Experimental & 43 & 16.71 & 6.01 & \multirow{2}{*}{9.11} & \multirow{2}{*}{$* * 0.001$} \\
\cline { 2 - 7 } & Control & 38 & 10.22 & 5.22 & & \multirow{2}{*}{8.76} \\
\multirow{2}{*}{ Women } & Experimental & 43 & 20.35 & 3.57 & \multirow{2}{*}{0.002} \\
\cline { 2 - 5 } & Control & 38 & 17.22 & 3.31 & \\
\hline
\end{tabular}

* Statistically significant at $(0.05)$ level

** Statistically significant at (0.01) level

The data of the previous table indicate that there are statistical significant differences in the average results of children sample test at the level of originality on the creative thinking test in form (A), due to the implementation of the brain keys program, where the level of significance reached (0.001). In favor of the experimental group in which the brain keys program was applied. The average results of children sample (10.22) before the application of the brain keys program (control group), and reached after the application of the brain keys program (16.71) (experimental group), and this indicates the impact of the brain keys program in the creative thinking development in children, this impact has reached $(64 \%)$.

The data of the previous table indicate that there are statistical significant differences in the average results of women sample test at the level of originality on the creative thinking test in form (A), due to the implementation of the brain keys program, where the level of significance reached (0.002). In favor of the experimental group in which the brain keys program was applied. The results of women sample (17.22) before the implementation of brain keys program (control group), and after the application of the brain keys program (20.53) (experimental group), and this indicates the impact of the brain keys program in the creative thinking development in women, this impact has reached (19\%).

Table (4): $t$ - test of the control and experimental groups on the creative thinking test at Originality level (Image format B)

\begin{tabular}{|c|c|c|c|c|c|c|}
\hline Level & Group & No & Mean & S. Deviation & (t) value & Sig. value \\
\hline \multirow{2}{*}{ Children } & Experimental & 43 & 47.58 & 11.51 & \multirow{2}{*}{14.58} & \multirow{2}{*}{$* * 0.000$} \\
\cline { 2 - 7 } & Control & 38 & 40.41 & 11.22 & & \multirow{2}{*}{15.11} \\
\multirow{2}{*}{ Women } & Experimental & 43 & 40.35 & 13.17 & \multirow{2}{*}{0.000} \\
\cline { 2 - 5 } & Control & 38 & 34.21 & 12.89 & & \\
\hline
\end{tabular}

* Statistically significant at (0.05) level

** Statistically significant at (0.01) level

The data of the previous table indicate that there are statistical significant differences in the average results of the test of children sample at the level of originality on the creative thinking test in form (B), due to the application of the brain keys program, where the level of significance reached (0.000). The experimental group in which the brain keys program was applied. 
The average results of children sample (40.41) before the application of the brain keys program (control group), and reached after the application of the brain keys program (47.58) (experimental group), and this indicates the impact of the brain keys program in the creative thinking development in children, this impact has reached (18\%). The data of the previous table indicate that there are statistical significant differences in the average results of the test of women sample at the level of originality on the creative thinking test in form (B), due to the application of the brain keys program, where the level of significance reached (0.000). In favor of the experimental group in which the brain keys program was applied. The results of women sample (34.21) before the implementation of the brain keys program (control group), and reached after the application of the brain keys program (40.35) (experimental group), and this indicates the impact of the brain keys program in the creative thinking development in women, this impact has reached (18\%).

\section{Results of the third hypothesis and discussed:}

The third hypothesis of the study: There is no statistical significant effect at the level of $(\alpha \leq 0.05)$ of the Brain Keys Program Implementation to the Creative Thinking Development at the level of adding details on the Torrance scale among the study sample. To validate this hypothesis, an independent sample t-test was performed. The results are shown in Tables (5) and (6).

Table (5): $t$ - test of the control and experimental groups on the creative thinking test at Elaboration level (Image format A)

\begin{tabular}{|c|c|c|c|c|c|c|}
\hline Level & Group & No & mean & S. Deviation & (t) value & Sig. value \\
\hline \multirow{2}{*}{ Children } & Experimental & 43 & 22.36 & 5.22 & \multirow{2}{*}{10.27} & \multirow{2}{*}{$* * 0.000$} \\
\cline { 2 - 7 } & Control & 38 & 15.57 & 5.02 & & \multirow{2}{*}{10.54} \\
\multirow{2}{*}{ Women } & Experimental & 43 & 29.65 & 3.77 & \multirow{2}{*}{$* 000$} \\
\cline { 2 - 5 } & Control & 38 & 22.41 & 3.25 & & \\
\hline
\end{tabular}

* Statistically significant at (0.05) level

** Statistically significant at (0.01) level

The data of the previous table indicate that there are statistical significant differences in the average results of children sample test at the level of detail on the creative thinking test in Figure (A), due to the application of the brain keys program, where the level of significance (0.000). In favor of the experimental group in which the brain keys program was applied. The average results of children sample (15.57) before the implementation of the brain keys program (control group), and reached after the application of the brain keys program (22.36) (experimental group), and this indicates the impact of the brain keys program in the creative thinking development in children, this impact has reached (44\%).

The data of the previous table indicate that there are statistical significant differences in the average results of women sample test at the level of detail on the creative thinking test in form (A), due to the application of the brain keys program, where the level of significance reached (0.000). In favor of the experimental group in which the brain keys program was applied. The results of women sample (22.41) before the implementation of the brain keys program (control group), and after the application of the brain keys program (29.65) (experimental group), and this indicates the impact of the brain keys program in the creative thinking development in women, this impact has reached (32\%).

Table (6): $t$ - test of the control and experimental groups on the creative thinking test at Elaboration level (Image format B)

\begin{tabular}{|c|c|c|c|c|c|c|}
\hline Level & Group & No & mean & S. Deviation & (t) value & Sig. value \\
\hline \multirow{2}{*}{ children } & Experimental & 43 & 32.65 & 7.61 & \multirow[b]{2}{*}{15.66} & \multirow[b]{2}{*}{$* * 0.000$} \\
\hline & Control & 38 & 25.88 & 7.14 & & \\
\hline \multirow{2}{*}{ Women } & Experimental & 43 & 31.59 & 12.28 & \multirow{2}{*}{14.87} & \multirow{2}{*}{$* * 0.000$} \\
\hline & Control & 38 & 22.98 & 11.78 & & \\
\hline
\end{tabular}

* Statistically significant at (0.05) level

** Statistically significant at $(0.01)$ level

The data of the previous table indicate that there are statistical significant differences in the average results of children sample test at the level of detail on the creative thinking test in form (B), due to the application of the brain keys program, where the level of significance (0.000). 
The experimental group in which the brain keys program was applied. The average results of children sample (25.88) before the implementation of the brain keys program (control group), and reached after the application of the brain keys program (32.65) (experimental group), and this indicates the impact of the brain keys program in the creative thinking development in children, this impact has reached $(26 \%)$.

The data of the previous table indicate that there were statistical significant differences in the average results of women sample test at the level of detail on the creative thinking test in form (B), due to the application of the brain keys program, where the level of significance (0.000). In favor of the experimental group in which the brain keys program was applied. The results of women sample (22.98) before the implementation of the brain keys program (control group), and after the application of the brain keys program (31.59) (experimental group), and this indicates the impact of the brain keys program in the creative thinking development in women, this impact has reached $(37 \%)$.

\section{Conclusion and Discussion}

The study reached a set of results, as follows:

- There are statistical significant differences in the mean results of children and women sample test at the level of flexibility on the creative thinking test in its formative forms (A and B), due to the application of the brain keys program. This indicates that there is a statistical significant effect at the level of $(\alpha \leq 0.05)$ for the application of the brain key program at the level of flexibility in the creative thinking development on the Torrance test among study sample. This result is consistent with all DeBono's creative thinking programs, (DeBono, 2003).

- There are significant differences in the mean results for children and women sample test at the level of originality on the creative thinking test in its formative forms (A and B), attributed to the application of the brain keys program, where these differences tend to favor the experimental group. This indicates that there is a statistical significant effect at the level of significance $(\alpha \leq 0.05)$ for the application of the brain keys program at the level of originality in the creative thinking development on the Torrance test among study sample. This current study result is consistent with the study's results of Khawaldeha, \& Ruzlan, (2016), and Hegazy (2012).

- There are significant differences in the mean results of children and women sample test at the level of detail on the creative thinking test in its formative forms (A and B), attributed to the application of the brain keys program, and these differences tend to favor the experimental group. This indicates that there is a statistical significant effect at the level of significance $(\alpha \leq 0.05)$ for the application of the brain keys program at the detailed level of the creative thinking development on the Torrance test among the study sample. This result means the positive and effective effect of the brain keys program, which raised the level of creative thinking among the study sample.

\section{Recommendations}

- Encouraging and supporting the students in using creative thinking in their Learning process and problems solving.

- Submitting educational and psychological programs, in addition to scales for creative thinking development among students in the different academic stages.

- Working on brain keys program by using generalization among students' at all academic levels, from school to university because of the real influence in the creative thinking development.

\section{References}

Al-khadraa, Fadia. (2005). Development of Innovative and Critical Thinking (Empirical Study), Debono Publishing and Distribution, Amman, Jordan.

Al-Rashidi, Huda, Al-Khalidi, Mariam, and Zyoudi, Mohammed (2015) The level of creative thinking among gifted students in the secondary school in Tabuk, Saudi Arabia, in light of some variables, 19-21 May, United Arab Emirates University.

Al-Rubaie, Farah. \& Daniel, Esther, (2014). Developing a Creative Thinking Test for Iraqi Physics Students, International Journal of Mathematics and Physical Sciences Research, 2 (1), 80-84, Available at: www.researchpublish.com

Al-Sameer, Mohammed, (2003). Effectiveness of a training program for the development of creative thinking skills among 10th grade students in Jordan, unpublished PhD thesis, Amman Arab University, Amman. 
Al-Atoum, Adnan. (2004). Cognitive Psychology and Theory of Application, 1ed, Amman, Jordan: Dar Al Masirah for Publishing and Distribution.

Coughlan, A. (2010). Learning to learn, creative thinking and critical thinking, office of the vice-president for learning innovation and registrar, America.

DE Bono, E. (1989). Teaching Thinking, $1^{\text {ed }}$, translated by Adel Abd Al-Hakim and Tawfiq Ahmad Al-Omari, Kuwait: Kuwait Foundation for the Advancement of Sciences.

DE Bono, E. (1996) .CoRt 1-6 nd, 2ed Mica management resources, U.K. inc Britain.

De Bono, E, (2003). The Curt Thinking Skills Program, New York Bergman, press.

Edgar, Don. Faulkner, Paula. Knobloch, Niel. \& Alan, Morgan. (2008). Creative thinking: opening up a world of thought, New York, USA.

Fisher R. (2005) Teaching Children to Think, (2nd ed), Cheltenham: Nelson Thorns, London.

George, F (1995). Models of Thinking, 5th ${ }^{\text {ed }}$. George Alien, \& Unwin, Ltd.

Guilford, J. P. (1985).Varieties of Creative Giftedness: Their Measurement and Development, Gifted Child Quarterly, 19, 107-121.

Hallajian, Mahdiye. (2016). The effects of computer games on increasing students' creative thinking, International Journal Of Humanities And Cultural Studies, (4) 2, 213-220.

Hamouri, Khalid. (2004). The impact of the curriculum in social studies on the development of critical thinking skills and attitudes towards it students of King Abdullah II School of Excellence in Zarqa, PhD thesis, Amman Arab University, Amman - Jordan.

Hegazy, Hanan. (2012). The impact of a proposed program for the development of creative thinking skills among high school students in Galilee schools, Unpublished Master Thesis, Amman Arab University, Amman, Jordan.

Jarwan, Fathi. (2002). Creativity, Amman: Dar Al feker for Printing and Publishing.

Jarwan, Fathi (2012). Talent, Excellence and Creativity, I (4), Amman, Jordan: Dar Al feker for Printing and Publishing.

Keer, B. A. (1997). Developing talents in girls and young women. In N. Colangelo \& G. A. Davis (Eds.), Handbook of gifted education (2nd ed., pp. 483-497). Boston: Allyn \& Bacon.

Khawaldeha. Hamzah, \& Ruzlan. Md, (2016). The Effect of SCAMPER Program on Creative Thinking among Gifted and Talented Students, International Journal of Sciences: Basic and Applied Research (IJSBAR), (30) 2, 48-58.

Lieu. Thi Bich, Nhat. Thi Ho, Robert J. Hurle, (2016). Teaching for Creativity Development: Lessons Learned from a Preliminary Study of Vietnamese and International Upper (High) Secondary School Teachers' Perceptions and Lesson Plans, Scientific Research Publishing, 1 (7), 1024-1043,

http://www.scirp .org /journal /cehttp://dx.doi.org/10.4236/ce.2016.7717

Lin, Cheng-Shih and Wu,Wei. (2016). Effects of Web-Based Creative Thinking Teaching on Students' Creativity and Learning Outcome, Eurasia Journal of Mathematics, Science \& Technology Education, 2016, 12(6), 1675-1684, doi: 10.12973/eurasia.2016.1558a.

Lipman ,M. (1998). Thinking in Education, $3^{\text {ed }}$, USA. Cambridge University Press.

Mawafi, Sawsan, Mohammed, Saber, Malaka, Hussein, (2003). "The Effect of the Internet Using on Some Mathematical Concepts Development and Innovative Thinking Ability among Female Teachers in the Faculty of Arts and Humanities for Girls in Jeddah - Literary Sections", Journal of Studies in Curriculum and Instruction, No. (85), p. (22-85).

Meshal, Ehab. (2011). Brain Keys Program (practical applications as a form of exercises, mental games), Awarded patent and intellectual property rights under No, (1622- 4- 2015) www.mental-aerobics.com .

Mincemoyer, C. \& Perkins. D. (2003). Assessing decision-making skills of youth. The Forum for Family and Consumer Issues, $8(1), 1-9$.

Morrison, Keith. (1996). Developing reflective practice in higher degree students through a learning journal, Studies in Higher Education, Vol 21, No 3, pp. 317-332 (16).

Paul, Richard, Elder Linda \& Bartell, Ted. (2004). A Brief of history of the ideal critical thinking, California teacher preparation for instruction, Retrieved August 28, 2017 from: www.criticalthinking.org.

Piaw, Chua Yan. (2014). Effects of gender and thinking style on students' creative thinking ability, Social and Behavioral Sciences, 116, 5135 - 5139 .

Qatami, Youssef, Qatami, Naifah, Jaber, Majid, Hamdi, Nazih, Subhi, Tayseer (1996). Creative Thinking, Al-Quds Open University, Palestine.

Salder, Willbert L. (1993). Awakening students critical thinking power through logic problems. Journal of Instruction Psychology, 20 (4), 354-367.

Stein, M.I. (2004). Stimulating Creativity: Individual procedure, Academic Press, N.Y.

Torrance E.P, (1979). Creativity in the Classroom, Washington, D.C: National Education Association.

Torrance, E. P., \& Ball, O. E, (2001). The Torrance Tests of Creative Thinking Streamlined (revised) manual, Figural A and B. Bensenville, IL: Scholastic Testing Service, Inc. 